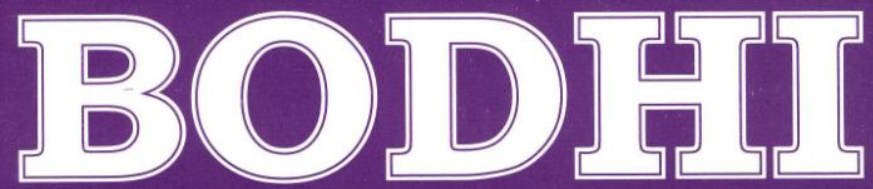

An Interdisciplinary Journal

ISSN: 2091-0479

Department of Languages and Mass Communication School of Arts

Kathmandu University

Bodhi, 4 (1), 1-17. ISSN 2091-0479. ㅇ 2010 Kathmandu University 


\section{Performing security in Nepal's little America: Bureaucracy and its malcontents ${ }^{1}$}

- Heather Hindman

Recent work by scholars in the disciplines outside of political science have questioned the often-simplistic understandings of "security" that are deployed in government and media realms. Nation-state bounded understandings of "border protection" seem inappropriate as more and more global conflict is defined in terms other than state-to-state warfare. In South Asia alone, violence in Kashmir, northern and eastern parts of Sri Lanka, India's so-called "Red Corridor" and nearly all of Nepal has demonstrated that political and social violence cannot be reduced to a war of state versus state. Yet, many of the tools of war and the ideas of security stem from an era when nationstates were (even if incorrectly) presumed to be the only salient actors. In an article entitled "On Vital Systems Security" Stephen Collier and Andrew Lakoff argue - in part relying on the work of Michel Foucault - that a new philosophy of security is slowly emerging among policy makers, one attendant to protecting institutions within the territory of the nation-state, even at the expense of the country itself and its

1 This is a variation of a paper first presented at the American Anthropological Association 2009 Annual Meeting, as part of a panel entitled "Bureaucracy and Befuddlement." I'd like to thank my fellow panelist, organizers Heath Cabot and Jessica O'Reilly, our discussant Susan Greenhalgh and especially our very engaged audience. I would also like to thank "John" and the many other guys who agreed to speak with me about the adventures at the Embassy as well as the U.S. Mission staff members and family. It was not only their stories but their frustration with the system and enthusiasm to be heard that encouraged me to write this piece - thanks for your honesty and friendship. I also thank Kashiraj Pandey for his many welcoming gestures and for our on-going exchanges. Any errors, omissions or general lack of clarity are purely my own. 
people (Collier and Lakoff, 2009, pp. 1-2). Thus, if formerly attention was paid to preserving territorial sovereignty or civilian populations, this new approach considers what "critical systems" would be most necessary to the on-going survival of the nation-state as a political and economic entity. This is not a trivial shift, as Collier and Lakoff suggest, as it transforms the idea of the state's responsibility from one of protecting people and territory to protecting things and money. These concerns over "vital systems" security transcend the boundaries of the nation-state, as governments worry about preserving the resources and networks that exist outside its borders that are nonetheless necessary to the functions of the state, such as energy sources, trade pathways and economic hubs. In addition to these explicit security concerns, I suggest that the government have another set of threats in mind as well. In this new age, the threat of the media and concerns with public perceptions are of equal weight with respect to health of the nation on a world stage. Both explicit military actions and more subtle forms of securitization are often discursive and performative acts, designed to be seen and heard outside the territory of the nation-state. A leader might propose a security action to see how it will be received in the media and public opinion, or enact a policy intended to attract global respect or attention.

This new and ever more complex idea of security and attendant diversity of responses has many implications for the current political situation in Nepal. Neighbors to the north and south of Nepal see actions inside the territory as threatening and have attempted to intervene, not to preserve territorial sovereignty, but to contain "ideological" threats. The weapons they wield against Nepal are not guns and bombs, but more often economic. Within Nepal, it is difficult to keep track of the ever-changing actors who are "threatening the nation." First of all, a more classic approach to security would demand an understanding of a governing institution that is singularly in command of security, a goal that it is proving challenging to establish (at the writing of this piece, round 17 of the Prime 
Ministerial elections have failed). Max Weber's famous definition of the state as the entity with a monopoly on the legitimate use of violence is difficult to parse given Nepal's situation of what I call "long-term provisionality." This is aside from the multiple military bodies operating within the country and the complexly intertwined polities of race, caste and class that are finding political voice, which nonetheless seem to produce the same few people in leadership positions. Even this lengthy enumeration of entities that are both threatened by and threatening to the nation-state neglects what are likely the greatest threats of Nepal: food, health, the environment and the economy.

Yet, I want to talk about something apart from all this, a security concern within the territory of Nepal but expressed by the United States Government - concern over the construction of a new Embassy complex in Kathmandu. Embassies, by their very nature, complicate issues of security and sovereignty, both in older understandings of territorial sovereignty-type security and as sites that impel more recent concerns over "vital systems." Garrett Mattingly, examining the history of diplomacy in the West (and many have subsequently borrowed the concept from his research), has noted that with the rise of a sense of the absolute and exclusive territorial sovereignty of the nation-state, the presence of foreign officials excepted from the rules of the state is a tense an anomalous situation. The exemption of ambassadors from state surveillance and ideas of diplomatic immunity require a sense of "extraterritoriality" in spaces like an embassy and only through such a logic might states be able to tolerate "within themselves little islands of alien sovereignty" (Mattingly, 1955, p. 282). ${ }^{2}$ For this reason, embassies offer some unique features for looking at global security and its bureaucratic implementation. In addition to

\footnotetext{
${ }^{2}$ Astute readers of scholarship on development in Nepal will note the echoes between this formulation and Nanda Shrestha's description of the U.S. Mission recreational complex as "Little America in the Heart of Nepal" (Shrestha 1997) and it is from Shrestha's invocation that my title derives.
} 
their situation as anomalous islands of foreign authority, embassies are also important sites for public performance of national ideals - a status that both exerts particular demands on them as well as subjecting them to special threats and scrutiny. The formal story of embassies as unique institutions and emblematic sites is but one contributing element to how U.S. Embassy security plays out in Nepal. Within and around all the formal protocols and structural requirements are the everyday lives of expatriate Americans who work for the U.S. Government or are family members of those who do. In trying to understand the stakes of security in Nepal not only from an official point of view but also in its everyday performances, I want to look at moments when the pomp and circumstance of the U.S. security apparatus was performed in the American diplomatic world in Kathmandu.

The story begins in 1999, although just by a few hours, in the midst of $\mathrm{Y} 2 \mathrm{~K}$ and the celebration of a new Millennium. Even in this moment of global anxiety about the potential for worldending events associated with computers as well as more mystical threats, discussion about security among expatriates in Nepal was often taken lightly. ${ }^{3}$ Many members of the foreign community who had gathered to celebrate remarked that they were happy to be spending this particular New Year in Kathmandu, said one "after all, it won't make much difference here if all the computers break." Perceiving themselves as already somewhat removed from the "global grid," jokes abounded about how the rest of the world might flock to Nepal if things went wrong when the year changed over. The moment of the Millennial New Year in Nepal was celebrated by the embassy staffs of Britain, Australia and the U.S. at a lavish "Gurkha Ball" held in one of the major hotels in Kathmandu. The British Army staff wore dress kilts for the event and entertained the crowd with antics until midnight. There was a

\footnotetext{
${ }^{3}$ One security issue on the mind of many in Nepal at this point in time, although strikingly absent from conversations on New Year's Eve, was the December 24, 1999 hijacking of an Indian Airlines flight outbound from Kathmandu's Tribhuvan International Airport.
} 
charity raffle, skits and a sumptuous dinner followed by dancing. Soon after the midnight toasts, one member of a U.S. Embassy staff excused himself, noting that he would be back in half an hour, but that he was required to report to his offices in Washington that the world had not come to an end in Nepal. He took one of the Marine Guards with him, several of them had been required to remain behind "in case of emergency" but were taking turns attending the party as their shifts changed.

There were plenty of potential security concerns that Western expatriates and foreign governments could have been focused on in Kathmandu in 1999 and 2000, but the attention of the Mission bureaucracy was focused elsewhere. Maoist violence which was to become the key issue of U.S. foreign policy in Nepal - was at the time seen to be mainly a rural issue and the frequent political protests in the capital were glossed as the "growing pains" of a young democracy. Among the U.S. expatriate community in Nepal at this time, most public discussions about safety addressed health scares, Kathmandu's horrible traffic and dangers elsewhere in the world that their diplomatic colleagues were encountering. ${ }^{4}$ The official addresses to a security agenda set by the central U.S. Government - such as reporting in the city had not been destroyed - were seen by many Mission professionals as administrative hassles, more connected to the bureaucracy of the Foreign Service than to everyday threats. Americans living in Kathmandu more frequently discussed smog, rabid dogs and the likelihood of intestinal distress as issues of security, rather that political violence or even the frequent bandhs. Even on the occasions when the U.S. Embassy would issue a bulletin warning about threats in rural areas, the need for these was

\footnotetext{
${ }^{4}$ The bombings of U.S. Embassies in Kenya and Tanzania in 1998 had frightened many in the official U.S. diplomatic core. The role that both businesses associated with the U.S., such as McDonalds, as well as official institutions of the U.S. Government might play as convenient targets for anti-American activists was brought to the forefront of discussions of U.S. security pundits by these events.
} 
often attributed to the irresponsible and lackadaisical attitudes of naïve tourists.

I first considered the means by which the U.S. official community performed security one day when a man came up and knocked on the window while I was having tea with an Embassy staffer at her home - startling me. She gave the strange man a friendly wave, but sighed a bit, noting to me, "I wish he wouldn't do that." Aside from the handbooks given out to Mission personnel on their arrival, the major concession to protecting the security of official U.S. government employees in Kathmandu was a security patrol - this is what had disrupted our tea. The patrol consisted of a private, uniformed security guard who checked in on both the homes of key personal and official buildings a few times a day. It had long been the practice of the Embassy to have some patrol of U.S. Mission homes and offices, but in 1999 the technology utilized in this practice was updated. The wife of diplomat explained the change to me, "they found out that some of the guys were skipping their route if the traffic was bad or it was a holiday they had to do something." The something that was introduced was the institution of an electronic scanning system, somewhat familiar now but a novelty at the time, in the U.S. and certainly in Nepal. The security guard was given a bar code reader and was required to scan a code posted on the various buildings to certify that he had made his rounds at a specified time. According to both the security guards and those guarded, this new technology had changed little in the daily practice of the patrol, other than producing new paperwork and surveillance of the surveillers.

The following year would change much about how risk, security and terror were seen globally, in the U.S. and in Nepal. The June 1, 2001 Royal Palace Massacre transformed both lives and politics in Nepal. The repercussions and implications of this tragedy are still being played out and debated, but the trauma of the event is unquestioned. The overwhelming violence that was the centerpiece of events in Naranyahiti Palace even attracted 
global attention to Nepalese politics, at a time when Nepal was more likely to appear in the travel section of foreign newspapers than on the front page. The U.S. immediately turned security attention to the situation in Nepal, establishing an "office of defence cooperation" soon after (Mage, 2007, p. 1836). Yet, the events of September 11, 2001 in the United States would soon overshadow this event and transform the terms upon which Nepali politics and global security could be discussed. With "terrorism" as the new watchword and the designation of various Maoist parties in Nepal as "other terrorist organizations" by the U.S. Government, security discussions between the two countries were transformed. In the following years, the U.S. provided nearly 20 million dollars in direct military assistance, training and military education. Subsequent agreements have promised even more money, the scale of which, according to some, has threatened to prolong the conflict (Chintan and Shrestha 2009). Yet, I want to again turn from these extremely important and much debated concerns to more trivial matters. Diplomacy and security are enacted not just in the formal zones of bipartisan declarations and aid agreements, but in everyday exchanges and the mundane but tangible expressions of security. ${ }^{5}$

By 2007, the U.S. Marine guard and private security guards with bar code scanners were not the only public displays of

${ }^{5}$ I offer only a slight apology for this second explicit diversion from the serious topics of security and policy in U.S.-Nepal relations. Throughout this piece I allude to, but ultimately avoid discussion of formal politics and conflict in favor of describing several small, but I hope illuminating, everyday performances of security in the world of the U.S. Mission in Nepal. Readers of Bodhi have many resources at their disposal that can provide erudite and divergent viewpoints on the controversial and disheartening events of the last decade and the formal reactions of the U.S. and Nepalese Governments. This anecdotally driven approach is both a result of where my own expertise lies as well as an attempt to offer a side long glance at polarizing issues. 
security within the U.S. Mission community. ${ }^{6}$ The threats had increased significantly in just a few short years and new discursive framings and bureaucratic appararti of security were being developed in response. Notably, the long planned but also long delayed building of a new U.S. Embassy complex was finally being put into motion. New facilities for the U.S. Mission were already being discussed in 1999, prompted in part by concerns about the earthquake vulnerability of many buildings in Kathmandu, including U.S. Mission buildings and houses. That Nepal was "overdue" for a catastrophic earthquake was a frequent topic of security discussions in the city, and foreigners often looked at the seemingly haphazard nature of construction in Kathmandu with trepidation, yet there was little done on an individual or institutional basis. One expatriate joked about his plans if such an earthquake were to devastate the infrastructure of the city, "I have some good shoes reserved for the trip and I know how to get to the Indian border."

It was not until 2005 that planning for the construction of a new U.S. Mission building that would take into consideration both earthquake and terrorism threats began in earnest, largely provoked by a more general project to strengthen the security at U.S. Embassies worldwide. The design, planning and construction of the Embassy involved many companies and

${ }^{6}$ Although I am neglecting the many events between 2000 and 2007, it seems necessary to mention two controversies, even in this parenthetical way, that undoubtedly influenced thinking about the Embassy construction. Accusations surfaced in 2006 that a Kuwaiti subcontracting company charged with the construction of the massive U.S. Embassy in Iraq was exploiting foreign workers, including Nepalis, as part of the construction process and in violation of a Nepalese government ban on Nepali overseas work in Iraq. The poor treatment of Nepali workers in particular was of interest to the media given the death of 12 Nepalis in Iraq who were being moved to the country, again in contravention of the Nepalese government ban, to be employed at U.S. Military bases, having passed through several labor management agencies. 
countries, regulations and recommendations, considerations and concerns, economics and environmentalisms. Although there are stories to be told about the politics behind the use of Nepalese firms, the history and geography of U.S. presence in the city and numerous other controversies, here I want to focus on the way in which replicability took precedence over aesthetics and focus the story on the experiences of just a few of men responsible for putting design into practice.

As part of the project of producing more secure U.S. facilities worldwide a U.S. architecture firm, Sorg and Associates, drew up plans for a modern and safe diplomatic facility. Parameters such as entrance barriers, guard booths, wall blast strength and electronic security were dictated by newly produced U.S. Government guidelines. The building blueprint took these requirements into account and generated the design for a safe and secure facility for the conduct of U.S. diplomacy in overseas locations. All of this effort exerted to consider security was taking place in Washington D.C. and the great number of concerns that had to be taken account of meant that little energy, money or time was left for aesthetics or local conditions. What Sorg produced was a blueprint for a new layout for U.S. Embassies that, it was hoped, could be used in ALL Embassies worldwide. As one builder working in Nepal noted - "it's like the three bears -- the only question is small, medium or large." The Sorg design could be scaled up and down depending on the site and the spatial needs of the Mission, without being fundamentally altered.

While there is much to be learned about the bureaucratics of U.S. diplomacy and the regulations and decision-making processes of the State Department and its Overseas Building Operations Office (OBO), much of what I learned of the complex negotiations over Embassy construction came from several of those directly responsible. This motley collection of middle-aged, mainly American men hung out at a local hotel bar every evening and discussed the travails of doing construction in Nepal. Most of the men, ranging in age from 
early twenties to late forties, were former U.S. Military personnel, which was not a coincidental fact. It was their military service that had made them eligible for the job, but also that was what generated much of the tension within the group.

There was much day-to-day conflict on the job site, prompted by everything from the variable weather, ethnic stereotypes, delays in the arrival of materials and debates over the relative skill level of coworkers. Overseeing much of the work were employees of the Turkish company Enka. Although Caddell Corporation, a U.S. firm, was the primary contractor, in Nepal they partnered with Enka as they had done on many U.S. Embassy construction projects. According to people I spoke with Caddell staffers were rarely seen; it was Enka's workers who directed the daily activities. Americans I talked to claimed that Enka's workers resented the U.S. and Canadian subcontractors and treated the Nepali workers "like slaves." The Nepali workers were frustrated with the lack of local input and the industrial design of the building, little suited to the site or the country. The Americans could not figure out who was in charge and claimed a complete lack of coordination between the different entities. Yet the most vociferous complaints heard from the American workers were not about either Nepali workers or the Turkish Enka staffers, but about their fellow Americans.

The reason why so many former U.S. Military personnel were involved in this project is because large portions of the construction and wiring of the Embassy were required to be done by people with a high level of U.S. security clearance. Nearly all the electrical work, much of the HVAC (Heating, Ventilating and Air Conditioning) work and even some basic construction for what were called the "secret squirrel" rooms had to be done by individuals with U.S. military clearance. The problem was, in 2006, there were long delays in obtaining security clearance for new applicants to the system and it was suggested that it was easier to teach people new skills than to struggle with the military and State Department bureaucracy. 
As a result, the cohort of people with both high levels of U.S. Government clearance and construction skills was fairly small. Most of the men who were hired on to the Embassy construction job in Nepal had met many times before, as they worked on the dozens of embassies that were being built or radically redesigned to fit the new security regulations. Despite, or perhaps because of, the frequency with which they crossed paths and their tendency to keep company only with other U.S. workers while abroad, much time was spent complaining about their American co-workers. One of the HVAC workers explained to me that he was worried about the work they were doing in Kathmandu, concerned that there might be fires as a result of how the electrical work was being done. John was one of the few members of the construction team who had worked on construction projects outside of the Embassy building boom and in his estimation the competency of his fellow American workers was very low. He noted that most of them had no knowledge of safety codes or inspection procedures, which had been the bane of his existence when doing work in the U.S. and were different than those that applied in Nepal. His complaints increased when a new HVAC worker arrived to help him, a man who announced the day he arrived that he knew nothing about HVAC systems, but had been willing to go to Nepal and had the necessary security clearance. John's accusations were more or less affirmed by some of those he accused. One employee noted that he had obtained the job based upon his military connections and that he did not know he would be working on wiring systems until after he was offered the job.

Fortunately, at least thus far, the Embassy has not burned down, although there have been quite a few controversies, including complaints about the building not meeting Nepalese environmental laws and investigations into corruption and inefficiency. ${ }^{7}$ For example, a significant reconstruction had to be done, one that took account of the ongoing earthquake

7 See Bikash Sangraula,"US Construction Ignores Nepal Law." Kathmandu Post November 14, 2006 and "Building Partnership." Spotlight Magazine June 23, 2006. 
threats that had not been fully accounted for in the centrally designed plans. The unusual soil conditions of Kathmandu and the use of local materials had created concerns that the building would not be quake resistant and a multi-million dollar retrofit was necessary. In addition, the new building has not been well received by the local population in Kathmandu. Although all that can be seen from the street is the 10 foot high walls and the signs in English and Nepali that no photography is allowed, articles have appeared in local newspapers decrying the industrial appearance of the building and snatches of graffiti on nearby walls declaim the site as one of "American Imperialism," written sometimes in Nepali and sometimes in English.

Spaces Magazine, ${ }^{8}$ a Nepalese magazine devoted to art and design, committed much of its September-October 2007 issue to reviewing the new U.S. Embassy, known as "Brahma Cottage," considering both the demands of a security driven architecture but also Nepal's many heritage sites and the impression the structure gives to Nepali passers-by as well as users of the facility. While the magazine's authors are quick to cite both Embassy staff and architectural critics, who emphasize that security is and must be the primary concern of the Embassy, they also worry that many in Nepal might look to this new construction in order to develop a new aesthetic for modern construction. Along this line, they find the building "indubitably disappointing," suggesting that it "disappoints the great expectations associated with America's predilection towards imposing and controversial architecture." In defending the domineering and uninviting character, the authors note that many in Nepal misunderstand the role of an Embassy building. Yet, I find much in the comments of the unnamed by-stander

\footnotetext{
${ }^{8}$ This issue of Spaces contains two articles directly on the Embassy, both entitled "Demystifying American Diplomacy" and both unattributed. In addition, the Editorial, by Uday Shrestha, addresses the demand for security as a priority at U.S. Embassies. All three pieces can be found at http://www.spacesnepal.com/archives/sep_oct07/index.htm.
} 
they quote who observes, "The infrastructures give an impression that it is some sort of international corporation... I don't think a diplomatic mission needs such a big investment in a small country like Nepal. I think a small and simple building would suffice."

My concern here is not with how to build a good Embassy or what the U.S. did or did not do wrong in the construction of Brahma Cottage. Instead, I point to both the way in which, even as security has become a global touchstone, it is also being transformed in its meaning and application. Echoing Collier and Lakoff, I want to open a dialogue about the contemporary relationship between security and the state, the way in which risk and risk management have become a central part of the work of governmentality in what several authors call "risk colonization" (Rothstein et al, 2006). Worry over risk, not merely as a threat to space and people but as a public performance, has become a dominant concern of many governments and in the attempt to mitigate one type of risk, others are often neglected or overlooked. ${ }^{9}$ This expansion of the domain of security and the importance of risk has generated many extensive bureaucratic apparati to ensure that all concerns are addressed, all danger detailed. This is impossible. Yet, the reaction to failed bureaucratic systems is often more bureaucracy as attempts are made to enumerate and mitigate that which can never be fully counted. As the literature on audit cultures suggests, bureaucracies are self-contained entities that can often only find solutions within themselves, thus the reaction to lacuna or failure is to produce more regulations and more bureaucracies. ${ }^{10}$

${ }^{9}$ The importance of risk as a philosophical concept in modern society has been extensively discussed by Ulrich Bech and Anthony Giddens. A convenient summary of the debates as well as an understanding of how risk and risk society play out in both Western and non-Western contexts can be found in Pat Caplan's edited volume Risk Revisited. ${ }^{10}$ See for example Marilyn Strathern's edited volume Audit Cultures and Karin Knorr Cetina's Epistemic Cultures both of which observe the way in which insular bureaucracies are able to inoculate 
Using several very idiosyncratic moments of expressions of security associated with the U.S. Mission and activities surrounding the construction of the U.S. Embassy complex in Maharajgung, I hope only to provide a bit of provocation at a moment of crisis in Nepal, a provocation for all to consider if current bureaucracies are effective and in whose interests they serve. In the changing relationship between what states worry about and the bureaucratic tools they use to address those risks, I see a trend. While security ideologies are consecutive (at least in their prioritization), security bureaucracies are cumulative. By this I suggest that with each passing day, attention is demanded by a new threat, a new type of concern, a new risk. Meanwhile, the bureaucracies that are established to respond to these risks often outlive the threat. Thus, even as ideologies of security drift into disfavor, their bureaucracies remain, with no one willing to be responsible for eliminating a procedure. Second, I call for attention to the relationship between security and safety. The distinction between these two forms might be the difference between the point of view taken by states and that of seen by individual actors, but I suggest it is also a story of the catastrophic and media-worthy event versus the less dramatic threats of everyday life. Unclean drinking water, maternal health and chaotic roadways continue to be major threats to the safety of most Nepalis, but they make poor newspaper articles and are rarely picked up by the international media. ${ }^{1}$

Finally, I want to raise concern about the creation of generalized security bureaucracies. In the construction of the U.S. Embassy in Nepal, security policy and its regulation is

themselves from failure and respond to setback without fundamentally questioning the on-going bureaucratic system.

${ }^{11}$ A trivial but amusing exception to this is the current broadcast in the United States on the History Channel of "IRT Deadliest Roads" that (over)dramatizes the travels of three Americans seeking to navigate trucks across the highways of Nepal, India, China, Afghanistan and Bhutan. http://www.history.com/shows/irt-deadliestroads/articles/the-roads 
made in the cosmopolitan center - in Washington D.C. - far from the concerns of local conditions and local people. These abstract dictums must then be applied in the particular, often in ways that threaten to negate their effectiveness. For example, one Embassy construction worker noted a regulation that required that vital materials must be collected from more than one supplier as well as that three times the needed amount should be procured, so that builders could randomly select what pipes or lumber would be used, in an attempt to protect against the sabotage of materials. This proved nearly impossible in Kathmandu, and individual responses to this demand varied, including ordering the overage and receiving inferior materials that had been hastily produced, using unauthorized suppliers merely to obtain the required overage, delays in construction as workers waited for materials to be manufactured and occasionally outright lying about the fulfillment of the regulation. As audit cultures and bureaucracies move through the world and across scales they become ends in themselves, affirmed by particular structures of authority. Like other audit cultures, security bureaucracies are self-reinforcing. Thus, security becomes what the security experts say it is and risk is managed by risk management professionals who affirm through their title and existence that "the government has everything under control."

What both the 1999/2000 and 2007 moments in the world of diplomatic Kathmandu suggest is the ambivalent presence of security bureaucracy in the everyday lives of expatriate Americans in Nepal. The paper tiger must be tamed! The management of security and risk bureaucracy is central to the job of diplomats, who influence and are influenced by the ideologies of security embedded within these structures. They discover new threats through the forms they are required to fill out; people who never thought to worry about how flood-prone their homes in Kathmandu might be develop new anxieties after filling out paperwork. Yet, they also have concerns that are unaddressed by the bureaucracy. Safety always threatens to escape its codification. The need for security - expressed in 
this situation in the form of clearance - created a new concerns and dangers through the risk of incompetence. The past dozen years have seen quite a number of fears arise in Kathmandu, a succession of security concerns that stem from diverse sources. Each one of the fears generates new bureaucracies that live on beyond the threat. This accumulation of bureaucratic responses to fear always threatens to bring back to life dormant security concerns or even create new ones - unforeseen children of the bureaucracy.

\section{References}

Beck, U. (1992). Risk society: Towards a new modernity. London: Sage.

Caplan, P. (Ed.) (2000). Risk revisited. Sterling, VA: Pluto Press.

Chintan, G. S., and Shrestha, N. (2009). The militarization of foreign aid. Nepal Policy Institute. Retrieved December 22, 2010, from http://npi.org.np/index.php?news\&nid=5.

Collier, S., and Lakoff, A. (2009). On vital systems security. Working paper of international affairs at the New School. Retrieved November 20, 2010, from http://www.gpia.info/files/u16/Collier_and_Lakoff_200 9-01.pdf.

Foucault, M. (2007). Security, territory, population: Lectures at the Collège de France 1977-1978. New York: Palgrave Macmillian.

Giddens, A. (1990). Consequences of modernity. Cambridge: Polity Press.

Knorr, C. K. (1999). Epistemic cultures: How the sciences make knowledge. Cambridge, MA: Harvard University Press.

Mage, J. (2007, May 19). The Nepali revolution and international relations. Economic and Political Weekly, 1834-1839.

Mattingly, G. (1955). Renaissance diplomacy. Boston: Houghton Mifflin Co. 
Rothstein, H., et al. (2006). A theory of risk colonization: the spiraling regulatory logics of societal and institutional risk. Economy and Society, 35(1), 91-112.

Shrestha, N. (1997). In the name of development: A reflection on Nepal. Kathmandu: Modern Printing Press.

Strathern, Marilyn ed. (2000) Audit cultures: Anthropological studies in accountability, ethics and the academy. New York: Routledge.

Weber, Max. (1964). The theory of social and economic organization. New York: The Free Press.

Dr. Hindman teaches in University of Texas at Austin, USA. 